\title{
The Influence of Health Care Policies and Health Care System Distrust on Willingness to Undergo Genetic Testing
}

\author{
Katrina Armstrong, MD ${ }^{1,2}$, Mary Putt, ScD ${ }^{1,3}$, Chanita Hughes Halbert, PhD ${ }^{2,4}$, David \\ Grande, MD ${ }^{1}$, J. Sanford Schwartz, MD ${ }^{1,2}$, Kaijun Liao, MS ${ }^{1}$, Noora Marcus, BA ${ }^{1}$, Mirar \\ Bristol Demeter, $\mathbf{M A}^{1}$, and Judy Shea, $\mathrm{PhD}^{1}$ \\ ${ }^{1}$ Department of Medicine, University of Pennsylvania \\ ${ }^{2}$ Abramson Cancer Center, University of Pennsylvania \\ ${ }^{3}$ Department of Biostatistics, University of Pennsylvania \\ ${ }^{4}$ Department of Psychiatry, University of Pennsylvania
}

\begin{abstract}
Purpose-As the potential role of genetic testing in disease prevention and management grows, so does concern about differences in uptake of genetic testing across social and racial groups. Characteristics of how genetic tests are delivered may influence willingness to undergo testing and, if they affect population subgroups differently, alter disparities in testing.
\end{abstract}

Methods-Conjoint analysis study of the effect of three characteristics of genetic test delivery (i.e. attributes) on willingness to undergo genetic testing for cancer risk. Data were collected using a random digit dialing survey of 128 African American and 209 White individuals living in the US. Measures included conjoint scenarios, the Revised Health Care System Distrust Scale (including the values and competence subscales), health insurance coverage, and sociodemographic characteristics. The three attributes studied were disclosure of test results to the health insurer, provision of the test by a specialist or primary care doctor, and race specific or race neutral marketing.

Results-In adjusted analyses, disclosure of test results to insurers, having to get the test from a specialist, and race specific marketing were all inversely associated with willingness to undergo the genetic test, with the greatest effect for the disclosure attribute. Racial differences in willingness to undergo testing were not statistically significant $(\mathrm{p}=0.07)$ and the effect of the attributes on willingness to undergo testing did not vary by patient race. However, the decrease in willingness to undergo testing with insurance disclosure was greater among individuals with high values distrust $(\mathrm{p}=0.03)$ and the decrease in willingness to undergo testing from specialist access was smaller among individuals with high competence distrust $(\mathrm{p}=0.03)$.

Conclusions-Several potentially modifiable characteristics of how genetic tests are delivered are associated with willingness to undergo testing. The effect of two of these characteristics vary according to the level of health care system distrust, suggesting that policy decisions about delivery of genetic testing may influence differences in uptake across patient subgroups defined by levels of distrust rather than by race.

Corresponding Author: Katrina Armstrong, MD, 1220 Blockley Hall, 423 Guardian Drive, Philadelphia, PA 19104, Tel: (215) 898-0957, Fax: (215) 573-8778, karmstro@mail.med.upenn.edu.

Publisher's Disclaimer: This is a PDF file of an unedited manuscript that has been accepted for publication. As a service to our customers we are providing this early version of the manuscript. The manuscript will undergo copyediting, typesetting, and review of the resulting proof before it is published in its final citable form. Please note that during the production process errors may be discovered which could affect the content, and all legal disclaimers that apply to the journal pertain. 


\section{INTRODUCTION}

The role of genetic susceptibility testing in health promotion and disease prevention is growing. ${ }^{1-4}$ Several advisory groups now support $B R C A 1 / 2$ testing for breast and ovarian cancer risk assessment and MLH1/MSH2 testing for colon cancer risk assessment in appropriate individuals. ${ }^{5-7}$ Access to genetic counseling was included in the preventive health services that must be covered by new insurance plans. ${ }^{8}$ Furthermore, disease associated single nucleotide polymorphisms identified by genome wide association studies may soon provide meaningful risk discrimination. ${ }^{9,10}$ Although genetic testing decisions require balancing potential benefits of genetic information with risks of unnecessary anxiety and follow up procedures, the number of clinically relevant genetic tests is likely to increase over the near future.

As the role of genetic testing grows, so does concern about differences in the uptake of testing across racial and socioeconomic groups. ${ }^{11-14}$ Several studies found that African American women are less likely to undergo BRCA1/2 testing than White women, even with a similar probability mutation. ${ }^{15-17}$ Other studies have documented differences in awareness and attitudes about genetic testing between African-Americans and Caucasians including lower awareness but greater concern about genetic discrimination among AfricanAmericans. ${ }^{18-23}$ This concern is linked to higher levels of health care related distrust among African Americans in general. ${ }^{24-30}$ A related body of literature has examined concerns about targeting of $B R C A 1 / 2$ testing among Ashkenazi women, demonstrating that a minority of Ashkenazi women were concerned about the focus on the Jewish community despite the higher prevalence of BRCA1/2 mutations. ${ }^{31-33}$

Disparities in health care utilization may be influenced by characteristics of the health care delivery system, some of which are potentially modifiable. ${ }^{34}$ One example of this relationship is the racial disparity in health insurance coverage. ${ }^{35}$ Patients with health insurance coverage are more likely to use health care and the provision of health insurance to minority groups can be modified by changes in health policy. However, there are also more subtle ways that decisions or policies about health care delivery may influence racial disparities. ${ }^{35}$ In the case of genetic testing, we hypothesized that policies that increase concern about adverse uses of genetic testing may widen some disparities, whereas policies that reduce such concerns may narrow disparities. Furthermore, policy effects may be particularly great for individuals with high levels of distrust of the health care system. ${ }^{36}$ Such policies might include access to test results by insurers or other groups, targeting genetic tests to specific racial groups (such as the Multisite BRACAnalysis for Ashkenazi individuals www.myriadpro.com/test-offerings), and the delivery of genetic tests by primary care providers. Each of these issues has been debated related to genetic test delivery in recent years, but little attention has been paid to how such policies might influence disparities in test utilization.

One potentially useful approach to understanding potential effects of such policies is through studies of their effect on preferences or intentions. Conjoint analysis provides a tool for understanding how differences in the attributes of a good or service can influence utilization decisions. ${ }^{37,3839-46}$ In conjoint analysis, consumers are asked to choose or rate a preferred good/service across scenarios that vary levels of different attributes of the good or service. ${ }^{47}$ In the current study, we used conjoint analysis to examine the effect of three attributes of genetic test delivery (insurer access to results, primary care provider vs. specialist, race specific vs. race neutral marketing) on willingness to undergo a genetic test for cancer susceptibility in a hypothetical clinical scenario. These attributes were chosen because they were under active discussion as policy alternatives at the time of data collection. The description of each of these attributes was simplified for the conjoint 
analysis but was designed to reflect the information that could be presented to a patient deciding about a genetic test. We were particularly interested in whether the effect of these potentially modifiable characteristics of genetic test delivery differed by patient race or level of health care system distrust.

\section{Methods}

We conducted a conjoint analysis study of African American and White adults identified through random digit dialing. The study population included a random national sample supplemented by samples from 40 Metropolitan Statistical Areas (MSAs). The conjoint study was part of a larger survey assessing the community determinants of health care system distrust. From the larger survey, participants were randomly selected to participate in the conjoint module. To identify the telephone numbers, a simple random sample of telephone numbers was selected from the frame of all possible telephone numbers within each sampling unit. The sampled telephone numbers were matched against a Yellow Pages database to remove business numbers from the sample.

\section{Study variables}

The genetic testing conjoint survey instrument was comprised of four parts.

1. Conjoint scenarios included three sections:(See Appendix) a brief introduction of genetic testing for cancer risk; a description of a hypothetical genetic test for cancer risk, specifying that the test was free and accurate and that there were treatments with only mild side effects available to prevent cancer among high risk individuals; eight different genetic test scenarios including all possible combinations of the two levels of the three attributes. For example, one scenario was "The test is only for people of your race, you must be seen by a specialist to get the test and the insurance companies can get your test results", and another was "The test is for people of all races, you get the test from your primary care doctor, and the insurance companies cannot get your test results." Participants were told that the scenarios would vary across the three attributes and that they would be asked how likely they would be to get tested in each of the scenarios on a scale of one to ten where one means very unlikely and 10 means very likely.

2. Health care system distrust was assessed using the Revised Health Care System Distrust Scale- a 9 item established scale ranging from a minimum of 9 (low distrust) to 45 (high distrust) (Cronbach's alpha 0.83). ${ }^{36}$ The scale includes two validated subscales: competence distrust (4 items with a range of 5 to 20 , Cronbach's alpha 0.77) that assessed perceptions of the technical competence of the health care system and values distrust (5 items with a range of 5 to 25 , Cronbach's alpha 0.73) that assessed the values of the health care system including the dimensions of the health care system's honesty, motives and equity.

3. Measures of health care access included whether the respondent currently had health insurance coverage, whether they had a personal doctor, whether they had gone without needed medical care in the past 12 months because of the cost. These items were derived from the National Health Interview Survey. ${ }^{48}$

4. Sociodemographic characteristics, including race, ethnicity, educational level, and income were assessed using established items. ${ }^{48}$ Whether the respondent lived with a partner was assessed using an item developed for this survey. For $59 \%$ of the sample, age was determined from publicly available data. For the remaining sample, age was imputed using a Markov Chain Monte Carlo method based on 
sociodemographics, health behavior, ethnicity, and race. ${ }^{49}$ Models including or excluding the age variable gave similar results.

\section{Data collection}

Data were collected using a Computer Assisted Telephone Interview between June 3, 2006 and December 21, 2006. Although conjoint analysis has traditionally been conducted using paper or internet data collection, phone collection has been used in several prior conjoint studies. ${ }^{50} \mathrm{We}$ used telephone data collection based upon a pilot study comparing the conjoint completion rate between two data collection strategies: the first completing conjoint items in a random digit dialing telephone contact, the second using a phone-mail-phone strategy with the participant identified through the random digit dialing survey, the conjoint instrument mailed to the participant, and the data collected in a subsequent phone call. Of the 80 participants in the phone only arm, all completed the survey. Of the 80 participants in the phone-mail-phone arm, 15 refused the mailed component and completed the survey in the initial call, 35 completed the conjoint survey in the second phone call and 30 could not be reached for the second phone call. Drop out in the phone-mail-phone arm was significantly higher among minority participants. Within each eligible household, an adult was randomly selected from the total number of adult males and adult females in the household identified by the answering party. The overall response rate for the full survey (i.e. proportion of completed plus partial interviews divided by the number of interviews plus the number of refusals plus the estimated eligible proportion of non-contacted households-AAPOR \#4) was $31.1 \% .{ }^{51}$ Of the 2,575 survey participants, 128 AfricanAmerican and 209 White participants were selected to participate in the genetic testing conjoint study. The demographic characteristics (i.e. gender, age, race, educational level) of the conjoint sample were not significantly different from those of the overall sample.

\section{Statistical analysis}

Characteristics of black and white respondents were compared using t-tests for continuous variables involving distrust, and chi-square tests for categorical variables. Linear regression investigated associations between the attribute levels and participant characteristics and the rating of likelihood of undergoing testing. Correlation between the eight conjoint scenarios nested within participant was taken into account using generalized estimating equations with an independence correlation structure. Models include the three test attributes, patient race, distrust score(s), and other sociodemographic variables including health insurance status, as well as interaction terms between the attributes and patient race and between the attributes and measures of health care system distrust. Wald tests were used to assess significance with a Type I error rate of 0.05 . The reported results are based on the robust standard error. Secondary analyses were conducted using an ordinal logit model adjusting for clustering of observations within participant with the dependent variable categorized either as low (1-3), moderate (4-7) or high (>7) or dichotomized as low (<5) vs. high ( $\geq 5)$ likelihood of undergoing the test. These results were substantively the same as the results using the linear models. All analyses were conducted in R or SAS.

\section{RESULTS}

Characteristics of the study participants are shown in Table 1. African-Americans and Whites had similar distributions of age, gender and measures of health care access but African-Americans were significantly less likely to be male, to have a college degree or higher, to have a partner and to be in the higher income categories. African-Americans had slightly higher distrust scores with a greater difference for the values than competence subscale and statistical significant differences for the continuous values distrust measure and the categorical overall distrust measure. 
Overall willingness to undergo genetic testing in the baseline scenario (primary care access, no disclosure of results to insurers, non race specific marketing) was moderately high (7.2 on scale from 0 to 10) and did not differ between races 6.90 for African Americans vs. 7.41 for Whites $(\mathrm{p}=.068)$. However, each of the policy alternatives studied (specialist access, disclosure of results to insurers, race specific marketing) negatively impacted the likelihood of undergoing testing, with the greatest effect for disclosure to insurance companies. Adding sociodemographic variables to this model had little impact on the significance of the test attributes. (Table 2) The effect of the policy alternatives did not differ by race (p-values for interaction terms $>0.10$ ).

In contrast, the effect of two of the policy alternatives varied according to levels of distrust, particularly the distrust subscales ( $\mathrm{p}$-values for interaction with competence and values scores $<0.05$ ). (Table 3 ) The adverse effect of specialist access on likelihood of testing was smaller among individuals with higher levels of overall health care system distrust $(\mathrm{p}=0.08$ for interaction) and particularly among individuals with higher levels of competence distrust ( $\mathrm{p}=.034$ for interaction). Access through a specialist led to a 0.34 unit decrease in likelihood of testing for individuals at the lowest decile of competence distrust but no change in likelihood for individuals at the ninth decile of competence distrust. In contrast, the adverse effect of insurance company disclosure was higher among individuals with higher levels of overall health care system distrust ( $\mathrm{p}=.053$ for interaction) and particularly among individuals with higher levels of values distrust ( $\mathrm{p}=.026$ for interaction). Disclosure to insurance companies led to a 1.06 unit decrease in likelihood of testing among individuals at the lowest decile of values distrust compared to a 2 unit decrease among individuals at the ninth decile of values distrust.

\section{DISCUSSION}

Utilization of predictive genetic testing remains an important issue for the translation of advances in genomics into improvements in disease prevention and chronic disease management. Concern exists about inequities in utilization across racial or socioeconomic groups as differential uptake of genetic testing may exacerbate existing health and health care disparities. Despite this concern, relatively little is known about what might be done to reduce disparities in utilization of genetic testing. In this study, self-reported likelihood of undergoing a hypothetical genetic test for cancer risk was lower in scenarios when the results are disclosed to the participant's health insurance company, when the test must be obtained from a specialist and when the test marketing is specific to the participant's racial group. However, the effect of these first two characteristics varied between people with different levels of health care system distrust, with individuals with high values distrust being particularly sensitive to the disclosure of results to insurance companies and individuals with high competence distrust being less sensitive to the need to obtain the test from the specialist. Although health care system distrust was slightly higher among African Americans than Whites (particularly values distrust), there were no differences in the effect of these characteristics between African Americans and Whites.

As hypothesized, certain characteristic of the delivery system reduce likelihood of undergoing genetic testing. Having to see a specialist to get the test increases the difficulty of obtaining the test and may raise concern about the cost of access. Disclosure of results to insurance companies is likely to raise concerns about insurance discrimination, which has been previously shown to be an important determinant of willingness to get tested. ${ }^{52}$ Race specific marketing also reduced likelihood of testing, an effect that was anticipated among African-Americans but was unexpected among Caucasians. 
Targeting of genetic testing to any racial or ethnic group may create concerns about the use of the test results for racial or ethnic discrimination. Although the discussion of these issues has generally focused on groups with a history of discrimination (e.g. African Americans, Ashkenazi Jews), these results suggest racial targeting concerns may exist even among majority groups and that presenting tests as specific to one group may paradoxically reduce uptake across all groups. ${ }^{33,53}$

Consistent with previous work, we found a small, marginally significant difference in willingness to undergo testing between African Americans and Whites in unadjusted analysis. ${ }^{21}$ However, this difference was not significant after adjustment and the effect of the attributes on likelihood of testing did not differ by race. It is possible that racial differences in willingness to undergo testing have abated over time as knowledge about genetic testing has become more widespread and testing availability has increased. These results also suggest that policies about the delivery of testing by primary care providers, the disclosure of test results to insurers and race specific test marketing are not likely to create or exacerbate racial differences in uptake.

In contrast, although the overall effect of health care system distrust on likelihood of undergoing genetic testing was also relatively small and marginally significant, the strength of that association depends upon both whether the test is delivered by a primary care provider or a specialist and on whether the test results are disclosed to insurers. If test results are disclosed to health insurers, individuals with high values distrust will be particularly discouraged from undergoing testing. Values distrust encompasses concerns about the motives of the components of the health care system including insurers and it is not surprising that it heighten concerns about how insurers will use genetic test results. ${ }^{36}$ Given that disclosure to insurers lowers utilization overall, a policy that restricts disclosure of test results should both increase likelihood of test utilization and reduce disparities in utilization by health care system distrust. If the test is delivered by specialists, individuals with low competence distrust will be less likely to undergo testing whereas those with high competence distrust will be unaffected. One possible explanation for this finding is that while accessing specialists is inconvenient for all respondents, individuals who distrust the overall competence of the health care system place a greater utility on obtaining specialist input as specialists are often seen as having greater competence in their area of expertise. Thus, the overall effect of primary care provider delivery is to increase likelihood of testing, but mostly driven by those with low competence distrust. While it is accepted that disparities by race and socioeconomic status are problematic, the importance of differences in utilization by health care system distrust alone is uncertain. It is not clear that individuals with higher levels of health care system distrust represent a disadvantaged population or whether differences in utilization across distrust levels represent a socially unacceptable source of variation.

In addition, this study suggests that conjoint analysis may be a useful method for testing the potential effects of different decisions about health care delivery on utilization, including differential utilization among population subgroups. Conjoint analysis has been used extensively in marketing to predict future purchasing behavior, as well as to identify how preferences vary across subgroups- a process often termed market segmentation. Although this study does not allow us to test whether the preferences for the attributes of genetic testing would translate into actual behavior, the results have considerable face validity and the ability to assess conjoint scenarios for this relatively complex topic through a random digit dialing survey increases the feasibility of this method for other questions.

This study has several limitations. As noted above conjoint analysis measures preferences not actual behavior. Rates of genetic testing have been shown to be substantially lower than 
what was predicted based upon studies of preferences or intentions. However, the focus of the conjoint analysis is on the relative effect of different attributes rather than the absolute rate of testing. The response rate was relatively low and it is possible that non-responders differed from responders. We did not have data on non-responders to assess for the degree of response bias. Because conjoint analysis is a within-subject experimental design, the results are likely to be valid within the sample but may not generalize outside of the sample. We conducted the data collection by telephone because of concerns about completion rates using a phone-mail-phone strategy, particularly among minority participants. However, it is possible that the validity of the results could be affected by difficulty completing the conjoint scenarios without visual items. These data were collected in 2006 before the Genetic Information Non-discrimination Act of 2008. This legislation prevents discrimination by employers and health insurers on the basis of genetic information and may have reduced the adverse impact of insurance company disclosure on likelihood of testing.

In summary, willingness to undergo genetic testing is associated with several modifiable characteristics of how the tests are delivered. The effect of two of these characteristics (disclosure of test results to insurers and specialist vs primary care access) are modified in very specific patterns by values and competence distrust respectively), indicating that policy decisions about delivery of genetic testing may have differential effects across patients and may either widen or narrow existing disparities in testing utilization.

\section{Acknowledgments}

Support: R01 HG 2689-01 from the National Human Genome Research Institute

\section{APPENDIX: Conjoint scenarios \\ Introduction to genetic testing}

"Now I'd like to talk about genes and genetics for a moment. You inherit some things, like your hair color or blood type, from your parents, through your genes. You can also inherit an increased chance of certain diseases, like cancer. Now, there are blood tests that can tell you if you have an increased chance of getting cancer because of the genes that you inherited from your parents. These are called genetic tests."

\section{Description of hypothetical genetic test}

"Now we would like you to imagine that you are considering getting a genetic test for cancer risk. The genetic test does not cost you any money and accurately predicts your chances of getting cancer in the future. There are treatments available to prevent your getting cancer, if the test shows you have a high chance of getting it. Although these treatments may have some side effects, they are mild.

I'm going to tell you some things about the genetic test and then I will ask you, based on those things, how likely you would be to get that genetic test. Let's use a scale of one to ten where one means you would be very unlikely to get the genetic test, and ten means that you would be very likely to get the test. "

\section{Eight different testing scenarios randomly ordered by the computer assisted telephone interview program}

"The test is only for people of your race, you must be seen by a specialist to get the test and the insurance companies can get your test results. 
The test is only for people of your race, you must be seen by a specialist to get the test and the insurance companies cannot get your test results.

The test is only for people of your race, you get the test from your primary care doctor and the insurance companies cannot get your test results.

The test is only for people of your race, you get the test from your primary care doctor and the insurance companies can get your test results.

The test is for people of all races, you must be seen by a specialist to get the test and the insurance companies can get your test results.

The test is for people of all races, you must be seen by a specialist to get the test and the insurance companies cannot get your test results.

The test is for people of all races, you get the test from your primary care doctor and the insurance companies can get your test results.

The test is for people of all races, you get the test from your primary care doctor and the insurance companies cannot get your test results."

\section{REFERENCES}

1. Hamburg MA, Collins FS. The path to personalized medicine. N Engl J Med. 2010; 363:301-304. [PubMed: 20551152]

2. Feero WG, Guttmacher AE, Collins FS. Genomic medicine--an updated primer. N Engl J Med. 2010; 362:2001-2011. [PubMed: 20505179]

3. Devilee P, Rookus MA. A tiny step closer to personalized risk prediction for breast cancer. N Engl J Med. 362:1043-1045. [PubMed: 20237351]

4. Gazdar AF. Personalized medicine and inhibition of EGFR signaling in lung cancer. N Engl J Med. 2009; 361:1018-1020. [PubMed: 19692681]

5. American Society of Clinical Oncology policy statement update: genetic testing for cancer susceptibility. J Clin Oncol. 2003; 21:2397-2406. [PubMed: 12692171]

6. Genetic risk assessment and BRCA mutation testing for breast and ovarian cancer susceptibility: recommendation statement. Ann Intern Med. 2005; 143:355-361. [PubMed: 16144894]

7. Recommendations from the EGAPP Working Group: genetic testing strategies in newly diagnosed individuals with colorectal cancer aimed at reducing morbidity and mortality from Lynch syndrome in relatives. Genet Med. 2009; 11:35-41. [PubMed: 19125126]

8. [Accessed October 30 2010] at http://www.healthcare.gov/law/about/provisions/services/background.html\#cover

9. Ku CS, Loy EY, Pawitan Y, Chia KS. The pursuit of genome-wide association studies: where are we now? J Hum Genet. 2010; 55:195-206. [PubMed: 20300123]

10. Manolio TA. Genomewide association studies and assessment of the risk of disease. N Engl J Med. 2010; 363:166-176. [PubMed: 20647212]

11. Olaya W, Esquivel P, Wong JH, et al. Disparities in BRCA testing: when insurance coverage is not a barrier. Am J Surg. 2009; 198:562-565. [PubMed: 19800469]

12. Suther S, Kiros GE. Barriers to the use of genetic testing: a study of racial and ethnic disparities. Genet Med. 2009; 11:655-662. [PubMed: 19752639]

13. Hall MJ, Olopade OI. Disparities in genetic testing: thinking outside the BRCA box. J Clin Oncol. 2006; 24:2197-2203. [PubMed: 16682739]

14. Shields AE, Burke W, Levy DE. Differential use of available genetic tests among primary care physicians in the United States: results of a national survey. Genet Med. 2008; 10:404-414.

[PubMed: 18496223] 
15. Armstrong K, Micco E, Carney A, Stopfer J, Putt M. Racial differences in the use of BRCA1/2 testing among women with a family history of breast or ovarian cancer. Jama. 2005; 293:1729_ 1736. [PubMed: 15827311]

16. Susswein LR, Skrzynia C, Lange LA, Booker JK, Graham ML 3rd, Evans JP. Increased uptake of BRCA1/2 genetic testing among African American women with a recent diagnosis of breast cancer. J Clin Oncol. 2008; 26:32-36. [PubMed: 18165638]

17. Halbert CH, Kessler L, Stopfer JE, Domchek S, Wileyto EP. Low rates of acceptance of BRCA1 and BRCA2 test results among African American women at increased risk for hereditary breastovarian cancer. Genet Med. 2006; 8:576-582. [PubMed: 16980814]

18. Kaplan CP, Haas JS, Perez-Stable EJ, et al. Breast cancer risk reduction options: awareness, discussion, and use among women from four ethnic groups. Cancer Epidemiol Biomarkers Prev. 2006; 15:162-166. [PubMed: 16434605]

19. Zimmerman RK, Tabbarah M, Nowalk MP, et al. Racial differences in beliefs about genetic screening among patients at inner-city neighborhood health centers. J Natl Med Assoc. 2006; 98:370-377. [PubMed: 16573301]

20. Rose AL, Peters N, Shea JA, Armstrong K. Attitudes and misconceptions about predictive genetic testing for cancer risk. Community Genet. 2005; 8:145-151. [PubMed: 16113531]

21. Peters N, Rose A, Armstrong K. The association between race and attitudes about predictive genetic testing. Cancer Epidemiol Biomarkers Prev. 2004; 13:361-365. [PubMed: 15006909]

22. Wideroff L, Vadaparampil ST, Breen N, Croyle RT, Freedman AN. Awareness of genetic testing for increased cancer risk in the year 2000 National Health Interview Survey. Community Genet. 2003; 6:147-156. [PubMed: 15237199]

23. Pagan JA, Su D, Li L, Armstrong K, Asch DA. Racial and ethnic disparities in awareness of genetic testing for cancer risk. Am J Prev Med. 2009; 37:524-530. [PubMed: 19944919]

24. Armstrong K, McMurphy S, Dean LT, et al. Differences in the patterns of health care system distrust between blacks and whites. J Gen Intern Med. 2008; 23:827-833. [PubMed: 18299939]

25. Rajakumar K, Thomas SB, Musa D, Almario D, Garza MA. Racial differences in parents' distrust of medicine and research. Arch Pediatr Adolesc Med. 2009; 163:108-114. [PubMed: 19188641]

26. Halbert CH, Weathers B, Delmoor E, et al. Racial differences in medical mistrust among men diagnosed with prostate cancer. Cancer. 2009; 115:2553-2561. [PubMed: 19296516]

27. Carpenter WR, Godley PA, Clark JA, et al. Racial differences in trust and regular source of patient care and the implications for prostate cancer screening use. Cancer. 2009; 115:5048-5059. [PubMed: 19637357]

28. Armstrong K, Ravenell KL, McMurphy S, Putt M. Racial/ethnic differences in physician distrust in the United States. Am J Public Health. 2007; 97:1283-1289. [PubMed: 17538069]

29. Halbert CH, Armstrong K, Gandy OH Jr, Shaker L. Racial differences in trust in health care providers. Arch Intern Med. 2006; 166:896-901. [PubMed: 16636216]

30. Voils CI, Oddone EZ, Weinfurt KP, Friedman JY, Schulman KA, Bosworth HB. Who trusts healthcare institutions? Results from a community-based sample. Ethnicity \& Disease. 2005; 15:97-103. [PubMed: 15720055]

31. Phillips KA, Warner E, Meschino WS, et al. Perceptions of Ashkenazi Jewish breast cancer patients on genetic testing for mutations in BRCA1 and BRCA2. Clin Genet. 2000; 57:376-383. [PubMed: 10852372]

32. Lehmann LS, Weeks JC, Klar N, Garber JE. A population-based study of Ashkenazi Jewish women's attitudes toward genetic discrimination and BRCA1/2 testing. Genet Med. 2002; 4:346352. [PubMed: 12394347]

33. Brandt-Rauf SI, Raveis VH, Drummond NF, Conte JA, Rothman SM. Ashkenazi Jews and breast cancer: the consequences of linking ethnic identity to genetic disease. Am J Public Health. 2006; 96:1979-1988. [PubMed: 17018815]

34. Medicine, Io, editor. Unequal Treatment: Confronting Racial and Ethnic Disparities in Health Care. Washington DC: The National Academies Press; 2002.

35. Armstrong K, Hughes-Halbert C, Asch DA. Patient preferences can be misleading as explanations for racial disparities in health care. Arch Intern Med. 2006; 166:950-954. [PubMed: 16682567] 
36. Shea JA, Micco E, Dean LT, McMurphy S, Schwartz JS, Armstrong K. Development of a revised Health Care System Distrust scale. J Gen Intern Med. 2008; 23:727-732. [PubMed: 18369678]

37. Green P, Srinivasan V. Conjoint analysis in marketing: New developments with implications for research and practice. Journal of Marketing. 1990; 54:3-19.

38. Green P, Srinivasan V. Conjoint Analysis in Consumer Research: Issue Outlook. Journal of Consumer Research. 1978; 5:103-123.

39. Bhargava JS, Bhan-Bhargava A, Foss AJ, King AJ. Views of glaucoma patients on provision of follow-up care; an assessment of patient preferences by conjoint analysis. Br J Ophthalmol. 2008; 92:1601-1605. [PubMed: 18664502]

40. Bridges JF. Stated preference methods in health care evaluation: an emerging methodological paradigm in health economics. Appl Health Econ Health Policy. 2003; 2:213-224. [PubMed: 15119540]

41. Phillips KA, Johnson FR, Maddala T. Measuring what people value: a comparison of "attitude" and "preference" surveys. Health Serv Res. 2002; 37:1659-1679. [PubMed: 12546291]

42. Ryan M, Farrar S. Using conjoint analysis to elicit preferences for heath care (Education and Debate). British Medical Journal. 2000; 320:1530-1533. [PubMed: 10834905]

43. Ryan M. A role for conjoint analysis in technology assessment in health care? Int J Technol Assess Health Care. 1999; 15:443-457. [PubMed: 10874373]

44. Bederman SS, Mahomed NN, Kreder HJ, McIsaac WJ, Coyte PC, Wright JG. In the eye of the beholder: preferences of patients, family physicians, and surgeons for lumbar spinal surgery. Spine (Phila Pa 1976). 35:108-115. [PubMed: 20042962]

45. Fraenkel L, Chodkowski D, Lim J, Garcia-Tsao G. Patients' preferences for treatment of hepatitis C. Med Decis Making. 30:45-57. [PubMed: 19636065]

46. Sassi F, McDaid D, Ricciardi W. Conjoint analysis of preferences for cardiac risk assessment in primary care. Int J Technol Assess Health Care. 2005; 21:211-218. [PubMed: 15921061]

47. Green, P.; Wind, J.; Rao, V. Conjoint Analysis: Methods and Application. Boca Raton, FL: CRC Press; 1999.

48. National Health Interview Survey Questionnaire. National Center for Health Statistics. 2001 at.

49. Schafer J. Analysis of Incomplete Multivariate Data. 1997

50. Wilson T. Collecting conjoint data through telephone interviews. Journal of the Academy of Marketing Science. 1984; 12:190-199.

51. Standard Definitions: Final Dispositions of Case Codes and Outcome Rates for Surveys. Lenexa, Kansas: The American Association for Public Opinion Research; 2004.

52. Armstrong K, Calzone K, Stopfer J, Fitzgerald G, Coyne J, Weber B. Factors Associated with Decisions about Clinical BRCA1/2 Testing. Cancer Epidemiol Biomarkers Prev. 2000; 9:12511254. [PubMed: 11097234]

53. Foster MW, Eisenbraun AJ, Carter TH. Genetic screening of targeted subpopulations: the role of communal discourse in evaluating sociocultural implications. Genet Test. 1997; 1:269-274. [PubMed: 10464656] 
Table 1

Participant characteristics.

\begin{tabular}{|c|c|c|c|c|}
\hline & Overall & $\begin{array}{c}\text { African } \\
\text { American } \\
\mathbf{N}=\mathbf{1 2 8}\end{array}$ & $\begin{array}{l}\text { White } \\
\mathbf{N}=209\end{array}$ & p-value \\
\hline Female $(\%)$ & 63.5 & 65.6 & 62.2 & 0.53 \\
\hline \multicolumn{5}{|l|}{ Age $(\%)$} \\
\hline $18-30$ & 3.0 & 3.9 & 2.4 & \multirow{6}{*}{0.06} \\
\hline $31-40$ & 6.8 & 10.2 & 4.8 & \\
\hline $41-50$ & 22.0 & 23.4 & 21.1 & \\
\hline $51-60$ & 33.8 & 32.0 & 34.9 & \\
\hline $61-70$ & 21.4 & 23.4 & 20.1 & \\
\hline$>70$ & 13.1 & 7.0 & 16.8 & \\
\hline \multicolumn{5}{|l|}{ Education (\%) } \\
\hline High school or less & 42.1 & 50.0 & 37.3 & \multirow{3}{*}{0.02} \\
\hline Some college & 27.6 & 28.1 & 27.3 & \\
\hline College or higher & 30.0 & 21.1 & 35.4 & \\
\hline Partner $(\%)$ & 56.1 & 43.8 & 63.6 & 0.0004 \\
\hline \multicolumn{5}{|l|}{ Annual Household Income (\%) } \\
\hline$<\$ 20,000$ & 21.4 & 27.3 & 17.7 & \multirow{6}{*}{0.005} \\
\hline$\$ 20,000-\$ 40,000$ & 19.0 & 25.0 & 15.3 & \\
\hline$\$ 40,001-\$ 60,000$ & 21.4 & 21.1 & 21.5 & \\
\hline$\$ 60,001-\$ 100,000$ & 20.8 & 14.8 & 24.4 & \\
\hline$>\$ 100,000$ & 11.0 & 5.5 & 14.4 & \\
\hline Unknown & 6.5 & 6.3 & 6.7 & \\
\hline Has health insurance $(\%)$ & 85.5 & 84.4 & 86.1 & 0.66 \\
\hline Has a personal physician (\%) & 86.4 & 86.7 & 86.1 & 0.87 \\
\hline \multicolumn{5}{|l|}{ Health care system distrust } \\
\hline Overall Distrust Scale ${ }^{a}$ & $26.8(26.1,27.5)$ & $27.6(26.5,28.7)$ & $26.3(25.4,27.2)$ & 0.06 \\
\hline High distrust (\%) & 20.8 & 26.6 & 17.2 & 0.04 \\
\hline Values Subscale $^{a}$ & $15.8(15.4,16.2)$ & $16.4(15.7,17.0)$ & $15.4(14.9,16.0)$ & 0.03 \\
\hline High values distrust (\%) & 18.7 & 22.7 & 16.3 & 0.14 \\
\hline Competence Subscale ${ }^{a}$ & $11.0(10.7,11.4)$ & $11.3(10.7,11.8)$ & $10.9(10.4,11.3)$ & 0.24 \\
\hline High competence distrust (\%) & 18.1 & 20.3 & 16.8 & 0.41 \\
\hline
\end{tabular}

${ }^{a}$ Median and interquartile range values (IQR). 
Table 2

Associations with Likelihood of Undergoing Testing

\begin{tabular}{|l|c|c|c|c|}
\hline & $\beta$ & p-value & \multicolumn{2}{|c|}{$95 \%$ CI } \\
\hline Conjoint attributes & & & & \\
\hline Race specific marketing & -0.39 & 0.00 & -0.56 & -0.23 \\
\hline Specialist access & -0.18 & 0.01 & -0.33 & -0.04 \\
\hline Insurance disclosure & -1.53 & 0.00 & -1.85 & -1.21 \\
\hline African American (vs. white) & -0.40 & 0.16 & -0.95 & 0.15 \\
\hline Female (vs male) & -0.23 & 0.38 & -0.76 & 0.29 \\
\hline Age & & & & \\
\hline $18-30$ (reference) & & & & \\
\hline $31-40$ & -1.52 & 0.08 & -3.20 & 0.16 \\
\hline $41-50$ & -0.51 & 0.44 & -1.81 & 0.79 \\
\hline $51-60$ & -0.81 & 0.23 & -2.11 & 0.50 \\
\hline $61-70$ & -0.46 & 0.51 & -1.82 & 0.91 \\
\hline$>70$ & -1.29 & 0.10 & -2.83 & 0.253 \\
\hline Education & & & & \\
\hline High school or less (reference) & & & & \\
\hline Some college & 0.61 & 0.07 & -0.04 & 1.26 \\
\hline College or higher & 0.21 & 0.58 & -0.55 & 0.97 \\
\hline Partner (vs no partner) & 0.02 & 0.95 & -0.56 & 0.60 \\
\hline Annual Household Income (\$) & & & & \\
\hline$<20,000$ (reference) & -0.04 & 0.07 & -0.08 & 0.003 \\
\hline $20,000-40,000$ & -0.38 & 0.40 & -1.25 & 0.50 \\
\hline $40,001-60,000$ & 0.46 & 0.36 & -0.52 & 1.44 \\
\hline $60,001-100,000$ & 0.47 & 0.41 & -0.65 & 1.58 \\
\hline$>100,000$ & & & & \\
\hline Unknown & & & -1.97 & 1.06 \\
\hline Health insurance coverage & & & & \\
\hline Health care system distrust (1 pt increase in scale) & & & & \\
\hline
\end{tabular}


Table 3

Difference in willingness to undergo genetic testing by attribute level and distrust

\begin{tabular}{|c|c|c|c|c|}
\hline Attribute levels & $\begin{array}{l}\text { Distrust } \\
\text { Scale }\end{array}$ & $\begin{array}{l}\text { Level of } \\
\text { Distrust } \\
\text { (decile) } b\end{array}$ & $\begin{array}{c}\text { Estimated effect of change } \\
\text { in attribute level on } \\
\text { willingness to undergo } \\
\text { testing } \\
(95 \% \text { CI })\end{array}$ & $\begin{array}{c}\text { P- } \\
\text { value }^{a}\end{array}$ \\
\hline \multirow{4}{*}{ Specialist vs primary care access } & \multirow{2}{*}{ Overall } & $1^{\text {st }}$ & $-0.35(-0.596,-0.112)$ & \multirow{2}{*}{$.082^{c}$} \\
\hline & & $9^{\text {th }}$ & $-0.02(-0.250,0.218)$ & \\
\hline & \multirow{2}{*}{ Competence } & $1^{\text {st }}$ & $-0.34(-0.54,-0.136)$ & \multirow{2}{*}{$.034^{d}$} \\
\hline & & $9^{\text {th }}$ & $0.07(-0.205,0.35)$ & \\
\hline \multirow{4}{*}{ Disclosure to insurance company vs no disclosure } & \multirow{2}{*}{ Overall } & $1^{\mathrm{st}}$ & $-1.13(-1.62,-0.637)$ & \multirow{2}{*}{$.053^{c}$} \\
\hline & & $9^{\text {th }}$ & $-1.92(-2.45,-1.39)$ & \\
\hline & \multirow{2}{*}{ Values } & $1^{\mathrm{st}}$ & $-1.06(-1.54,-0.583)$ & \multirow{2}{*}{$.026^{d}$} \\
\hline & & $9^{\text {th }}$ & $-2.00(-2.56,-1.45)$ & \\
\hline
\end{tabular}

${ }^{a}$ Based on the interaction between the test attribute and distrust variables

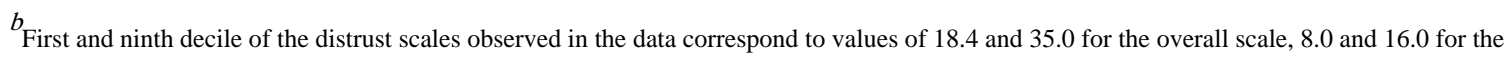
competence subscale, and 10.7 and 21.0 for the values subscale.

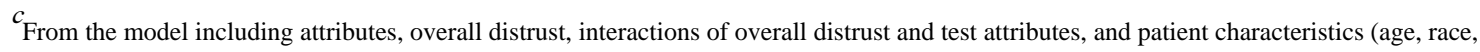
gender, education, income, partner, insurance status)

$d_{\text {Same model but with both distrust subscales (competence and values) instead of distrust }}$ 